\title{
Corticosteroid phobia among parents of asthmatic children
}

\author{
Deniz Özçeker ${ }^{1}$, Utkucan Uçkun ${ }^{2}$, Dürdane İslamova ${ }^{3}$, Zeynep Tamay ${ }^{1}$, Nermin Güler ${ }^{4}$ \\ ${ }^{1}$ Division of Pediatric Allergy and Clinical Immunology, ${ }^{2}$ Department of Pediatrics, Istanbul University Istanbul Faculty of \\ Medicine; ${ }^{3}$ Department of Pediatrics, Marmara University, Faculty of Medicine; ${ }^{4}$ Department of Pediatrics, İstanbul Bilim \\ University Faculty of Medicine, Istanbul, Turkey. E-mail: denizozceker@gmail.com \\ Received: 17th May 2017, Revised: 20th September 2017, Accepted: 8th October 2017
}

SUMMARY: Özçeker D, Uçkun U, İslamova D, Tamay Z, Güler N. Corticosteroid phobia among parents of asthmatic children. Turk J Pediatr 2018; 60: 142-146.

Asthma is one of the most prevalent chronic diseases among children. Its prevalence and morbidity have been rising in recent decades. Pediatric asthma causes a significant burden on families; allergen-avoidance measures, uncontrolled disease, and disease severity which are the major cost predictors of childhood asthma in Turkey. Inhaled corticosteroids (ICS) are considered as cornerstone medications in asthma management which reduce asthma morbidity and mortality. Our aim was to address corticosteroid phobia in caregivers of asthmatic children and its impact on asthma management.

Five hundred caregivers of asthmatic children were interviewed using structured questionnaire in this study.

Over fifty percent of the caregivers $(56.8 \%)$, most of whom $(82.6 \%)$ are already aware of using corticosteroids in their anti-asthma drug regimen, mentioned that they are afraid of using them. Almost one fourth of caregivers $(24.8 \%)$ made either some changes in their treatment regimen or stopped using the drugs due to corticophobia. Of the caregivers $55.2 \%$ had no idea about the side effects of corticosteroids and only $12.6 \%$ of them mentioned that they were informed by their physicians about the effects of corticosteroids. Any change in asthma treatment regimen due to corticophobia was found to be related with poor asthma control level (p: 0.004).

The impact of parental information about the effects and importance of steroids given by the physicians on better asthma control was found to be highly significant $(\mathrm{p}<0.001)$. That's why physicians and health care providers should spend enough time explaining the importance of adherence to treatment in asthma management, which may help in overcoming the fear of using ICS.

Key words: asthma, children, corticosteroids, phobia.

Asthma is one of the most prevalent chronic diseases among children. It is a heterogeneous disease, usually characterized by chronic airway inflammation. It is defined by the history of respiratory symptoms such as wheeze, shortness of breath, chest tightness and cough that vary in time and intensity, together with variable expiratory air flow limitation. ${ }^{1}$ According to the Global Burden of Asthma Report, the prevalence of asthma is between $1 \%$ and $18 \% .^{2}$ Studies held in Turkey demonstrated that there is a rising trend in childhood asthma prevalence. ${ }^{3,4}$ Asthma treatment guidelines have identified that the primary goal of management is to achieve overall asthma control. ${ }^{5}$ The benefits of good asthma control have been well studied and include reduced health-care resource utilization and loss of work/school days, higher probability of a normal quality of life, and reduced risk of exacerbations compared with poorly controlled asthma. ${ }^{6}$

Pediatric asthma causes a significant burden on families; allergen-avoidance measures, uncontrolled disease, and disease severity which are the major cost predictors of pediatric asthma in Turkey. ${ }^{7}$ Inhaled corticosteroids (ICS) are considered as corner stone medications 
in asthma management which reduce asthma morbidity and mortality. ${ }^{8}$ The use of inhaled medication in children has been shown to be safe and simple to be administered in the treatment of childhood asthma. Whereas, nonadherence to ICS is common and can result in persistent symptoms, increased number of missed school days, and increased urgent health-care visits. ${ }^{9}$ Although asthma guidelines recommend regular use of controller therapies in both adults and children with moderate to severe asthma, most of the patients with asthma discontinue asthma drugs for various reasons. Parental understanding of disease pathology and its management have been associated with greater adherence to the preventive regimen and decreased unscheduled medical visits or hospitalizations. ${ }^{10}$ Insufficient information of the parents is the major reason for noncompliance. The other reasons were concerns of the parents about the side effects of asthma drugs, reluctance of the children to use the drugs, and replacement or discontinuation of the drugs by another physician. ${ }^{11}$ Our aim was to address corticophobia in caregivers of asthmatic children and its impact on asthma management.

\section{Material and Methods}

Five hundred parents of 5-18-year-old asthmatic children were included in this study. The study was a cross-sectional survey of patients who had attended over a six-months period between February and June 2013 to the Pediatric Allergy and Immunology Unit in Istanbul University Hospital, Turkey. Children with a history of chronic respiratory disease other than asthma, prematurity and any co-existing disease which is also treated by corticosteroids were excluded from this study.

We used a structured questionnaire which was designed to evaluate the socio-epidemiologic data, asthma duration and treatment regimens. We used questions regarding: sources of information, attitude towards ICS, fears and concerns about long-term treatment with steroids. Oral personal interviews were conducted in Turkish by the same physician for each participant, who was not involved in the active treatment phases of the patients in the clinic by using the structured questionnaire. After completing the interview, caregivers were advised to contact their clinicians for further education and assurance about the importance and safety of steroids in asthma treatment. Written informed consents were obtained from all caregivers. This study was approved by Ethical Committee Consent of Istanbul Medical Faculty (2014/186).

\section{Statistical Analysis:}

In the evaluation of the qualitative and quantitative parameters, Student's t-test, paired t test, one-way ANOVA, Turkey and Pearson correlation analysis were used. Statistical analyses were made by using SPSS 21.0 software program (Licensed to Istanbul University). The threshold for significance was $\mathrm{p}<0.05$.

\section{Results}

There were 500 respondents (21 fathers, 479 mothers) to the questionnaire, and the response rate was $100 \%$. Demographic characteristics of the interviewed participants are shown in Table I. Of the participants; $5.9 \%$ (n: 29) were illiterate, $58 \%$ (n: 290) were graduated from primary schools and the rest were graduated either from high schools or universities. Most of the respondents $(79.4 \%, \mathrm{n}: 397)$ were stayat-home mothers.

Anti-asthma drugs were found to be administered mostly by the caregivers (74.2, $\% \mathrm{n:} 371$ ) whereas only $1.4 \%$ ( $\mathrm{n:} 7$ ) of children use their drugs on their own. A big majority of the caregivers (76\%) (n:380) claimed that they give the drugs on a regular basis and $58.2 \%$ ( $n$ : 291) of caregivers admitted that they also use alternative medicine. (herbal tea, honey etc.)

Over fifty percent of the caregivers (56.8\%), most of whom $(82.6 \%)$ are already aware of using corticosteroids in their anti-asthma drug regimen, mentioned that they are afraid of using them. Almost one fourth of caregivers (24.8\%) made either some changes in their treatment regimen or stopped using the drugs due to corticophobia. Moreover, $28.4 \%$ (n: 142 ) of the participants think that corticosteroids cause addiction.

Seventy-three two percent of the patients were referred from a secondary center, whereas $10.4 \%$ were referred either from public or private health institutions, $16.6 \%$ of patients 
Table I. Demographic Characteristics of The Studied Patients.

\begin{tabular}{lll}
\hline Age (years) mean+SD (range) & & $8.3 \pm 3.6(3-18)$ \\
\hline Number of household mean+SD (range) & & $4.3 \pm 1.1(2-10)$ \\
Male/Female, n & & $243 / 257$ \\
Follow up with, n (\%) & Pediatrician & $372(74.4 \%)$ \\
& Asthma & $70(14 \%)$ \\
& specialist & $58(11.6 \%)$ \\
& No follow & \\
& up & \\
Level of asthma control, n (\%) & Controlled & $34(6.8 \%)$ \\
& Partly & $225(45 \%)$ \\
& controlled & $241(48.2)$ \\
& Uncontrolled & \\
\hline
\end{tabular}

Table II. Other Drug Groups of Which the Caregivers Are Also Afraid.

\begin{tabular}{lc}
\hline Drugs & $\%(\mathrm{n})$ \\
\hline Antibiotics & $56.6(283)$ \\
Bronchodilators & $1.4(7)$ \\
Antitussives & $0.4(2)$ \\
More than one of the above & $6.4(32)$ \\
Others & $2.2(11)$ \\
None & $33(165)$ \\
\hline
\end{tabular}

were referred from another tertiary center.

Among participants, 34\% (n: 170) had other fears (darkness, bugs, claustrophobia etc) and $66.8 \%$ (n: 334 ) claimed that they are also afraid of other drugs (Table II).

More than half of the caregivers $(55.2 \%, \mathrm{n}$ : 276) had no idea about the side effects of corticosteroids. In contrast to $38.4 \%$ (n: 192) of the caregivers, $18 \%$ ( $\mathrm{n}$ : 90) claimed that there is no difference between using systemic and inhaled corticosteroids. The potential side effects of corticosteroids from caregivers' point of view are shown in Table III.

Only $12.6 \%$ (n: 63 ) of caregivers mentioned that they were informed by their physicians about the effects of steroids. The main sources of information for the rest were as follows; $80.4 \%$ from relatives or friends, $17 \%$ from social media or the internet and $2.2 \%$ from other sources (magazines, newspapers etc.).

According to the statistical analysis there were no relationships between corticophobia and caregivers' educational level (p: 0.066), occupation ( $\mathrm{p}:$ 0.678), information status from the physician (p: 0.383), usage of alternative medicine ( $p: 0.111$ ) presence of other fears (p: 0.643), respectively. However parental information given by the physician about steroids was related with better asthma control level of the child. $(p<0.0001)$

Presence of any change in asthma treatment regimen due to corticophobia was related with asthma control level of the child. (p: 0.004). However there was no relationship between corticophobia and asthma control level of the child (p: 0.218).

\section{Discussion}

Corticosteroid phobia results from the potential for systemic bioavailability as a result of chronic ICS use. Entry into the systemic circulation occurs in the lungs as well as through the gastrointestinal tract when the steroid particles are swallowed. ${ }^{12,13}$ Although reports are contradictory, some past research studies have indicated that inhaled steroid usage can decrease bone density, suppress childhood growth, suppress adrenal function, and cause 
Table III. The Potential Side Effects of Corticosteroids from Caregivers' Point of View.

\begin{tabular}{ll}
\hline & $\%(\mathrm{n})$ \\
\hline No idea & $55.2(276)$ \\
Weight gain & $25.4(127)$ \\
Failure to thrive & $11.4(57)$ \\
Organ toxicity & $2.8(14)$ \\
Edema & $2.2(11)$ \\
Osteoporosis & $0.8(4)$ \\
Dental caries & $0.6(3)$ \\
Allergic reactions & $0.4(2)$ \\
Cancer & $0.4(2)$ \\
Immunodeficiency & $0.2(1)$ \\
Skin changes & $0.2(1)$ \\
Psycological problems/hyperactivity & $0.2(1)$ \\
\hline
\end{tabular}

cataracts or glaucoma, as well as other adverse events. ${ }^{14-18}$ Current studies have indicated conflicting views on the aforementioned adverse events and have shown an improved risk-benefit ratio. In addition, newer steroid formulations have lower systemic bioavailability than older ICSs, because of several pharmacokinetic characteristics. ${ }^{14-17}$

Despite the latest study results, availability of newer steroid formulations and the unquestionable benefits of steroids for decreasing asthma mortality and morbidity, therapy adherence to steroids as asthma controller medication is still poor. ${ }^{13}$ In our study $24.8 \%$ (n: 124 ) of caregivers made either some changes in their treatment regimen or stopped using the drugs due to corticophobia. Medication adherence, in general, was found to be dependent on a patient's beliefs and concerns regarding their perceived disease severity and perceived treatment necessity. ${ }^{13,19,20}$ In our study we found that caregivers' perception of asthma and adherence to medication are directly related to asthma control level of the children ( $p<0.0001, p: 0.004$ respectively).

Steroid adherence studies have also showed that increased concerns towards medications and side effects are correlated with decreased therapy adherence. This includes not only patient concerns, but also parental and caregiver concerns in the case of the pediatric patients. Yoos et al. ${ }^{21}$ reported that one-third of the parents who have children with asthma would try to get their children off steroids as soon as possible. This probably results from incorrect perceptions of ICS safety profiles which in turn effects compliance to beneficial medication regimens. ${ }^{13,22-25}$
In our study $44.8 \%$ of parents have concerns about the side effects of ICS. We found out that, main potential side effects from caregivers' point of view are addiction (28.4\%), weight gain $(25.4 \%)$ and failure to thrive $(11.4 \%)$. Our findings have some similarities with Gazala et al. ${ }^{26}$ from Israel who found that $30.4 \%$ of mothers of asthmatic children reported fears and concerns with ICS, the reasons mentioned for their concerns were risk of addiction (64\%), weight gain or stunting $(50 \%)$, toxicity $(35 \%)$, and irritability or hyperactivity (57\%).

Moreover, our results revealed that; $34 \%$ ( $n: 170)$ of the caregivers have other fears (darkness, bugs, claustrophobia, etc.) and $66.8 \%$ (n: 334 ) claimed that they are also afraid of other drugs. Other than steroids, antibiotics $(56.6 \%)$ are the scapegoat drugs for caregivers. The most common sources of medical information in our population are friends or relatives. Only $12.6 \%$ ( $n$ : 63) of caregivers mentioned that they were informed by their physicians about the effects of steroids. This may strictly be related to the working conditions and timing problems of the physicians working in public institutions.

Based on the above concerns, communication between patients and health care providers is important to identify and change beliefs about steroid side effects that may be interfering with therapy adherence. It is important to communicate the role of asthma medications with patients and families, rather than just prescribing the names and doses of the drugs. ${ }^{27-29}$ 


\section{REFERENCES}

1. Global Initiative for Asthma (GINA) Program 2016. www.ginaasthma.org

2. Bousquet J, Bousquet PJ, Godard P, Daures JP. The public health implications of asthma. Bull WHO 2005; 83: 548-554.

3. Akcay A, Tamay Z, HocaogluAB, Ergin A, Guler N. Risk factors affecting asthma prevalence in adolescents living in Istanbul, Turkey. AllergolImmunopathol (Madr) 2014; 42: 449-458.

4. Ones U, Akcay A, Tamay Z, Guler N, Zencir M. Rising trend of asthma prevalence among Turkish school children (ISAAC phases I and III). Allergy 2006; 61: 1448-1453.

5. O'Byrne PM, Pedersen S, Schatz M, et al. The poorly explored impact of uncontrolled asthma. Chest 2013; 143: 511-523.

6. Bateman ED, Reddel HK, Eriksson G, et al. Overall asthma control: the relationship between current control and future risk. J Allergy Clin Immunol 2010; 125: 600-608.

7. Beyhun NE, Soyer OU, Kuyucu S, et al. A multi-center survey of childhood asthma in Turkey-I: The cost and its determinants. Pediatr Allergy Immunol 2009; 20: 72-80.

8. Suissa S, Ernst P. Inhaled corticosteroids: impact on asthma morbidity and mortality. J Allergy Clin Immunol 2001; 107: 937-944.

9. Rand CS. Non-adherence with asthma therapy: more than just forgetting. J Pediatr 2005; 146: 157-159.

10. Brook U, Mendelberg A, Heim M. Increasing parental knowledge of asthma decreases the hospitalization of the child: A pilot study. J Asthma 1993; 30: 45-49.

11. Cetinkaya F. Reasons for discontinuation of antiasthma drugs in children with asthma coming from lower socioeconomic classes in a developing country. Allergy Asthma Proc 2007; 28: 695-697.

12. Rizzo MC, Solé D. Inhaled corticosteroids in the treatment of respiratory allergy: Safety vs. efficacy. J Pediatr (Rio J) 2006; 82(5 Suppl): S198-S205.

13. Skoner JD, Schaffner TJ, Schad CA, Kwon AY, Skoner DP. Addressing steroid phobia: improving the riskbenefit ratio with new agents. Allergy Asthma Proc 2008; 29: 358-364.

14. Egan JJ, Maden C, Kaira S, Adams JE, Eastell R, Woodcock AA. A randomized, double-blind study comparing the effects of beclomethasone and fluticasone on bone density over two years. Eur Respir J 1999; 13: $1267-1275$.

15. Tattersfield AE, Town GI, Johnell O, et al. Bone mineral density in subjects with mild asthma randomised to treatment with inhaled corticosteroids or noncorticotsteroid treatment for twoyears. Thorax 2001; 56: $272-278$
16. Becker AB, Kuznetsova O, Vermeulen J, et al; Pediatric Montelukast Linear Growth Study Group. Lineargrowth in prepubertal asthmatic children treated with montelukast, beclomethasone, or placebo: A 56-week randomized double-blind study. Ann Allergy Asthma Immunol 2006; 96: 800-807.

17. Simons FE. A comparison of beclomethasone salmeterol, and placebo in children with asthma. Canadian Beclomethasone Dipropionate-Salmeterol Xinafoate Study Group. N Engl J Med 1997; 337: 1659-1665.

18. Philip J. The effects of inhaled corticosteroids on growth in children. Open Respir Med J2014; 8(Suppl 1: M3): 66-73.

19. Horne R, Weinman J. Patients' beliefs about prescribed medicines and their role in adherence to treatment in chronic physical illness. J Psychosom Res 1999; 47: 555- 567.

20. Clifford S, Barber N, Horne R. Understanding different beliefs held by adherers, unintentional nonadherers, and intentional nonadherers: Application of the NecessityConcerns Framework. J Psychosom Res 2008; 64: 41-46.

21. Yoos HL, Kitzman H, McMullen A. Barriers to antiinflammatory medication use in childhood asthma Ambul Pediatr 2003; 3: 181-190.

22. Menckeberg TT, Bouvy ML, Bracke M, et al. Beliefs about medicines predict refill adherence to inhaled corticosteroids. J Psychosom Res 2008; 64: 47-54.

23. Conn KM, Halterman JS, Fisher SG, Yoos HL, Chin NP, Szilagyi PG. Parental beliefs about medications and medication adherence among urban children with asthma. Ambul Pediatr 2005; 5: 306-310.

24. Peterson-Sweeney K, McMullen A, Yoos HL, Kitzman H. Parental perceptions of their child's asthma: Management and medication use. J Pediatr Health Care 2003; 17: 118-125

25. Conn KM, Halterman JS, Lynch K, Cabana MD. The impact of parents' medication beliefs on asthma management. Pediatrics 2007; 120: e521-e526.

26. Gazala E, Sadka R, Bilenko NR. Parents' fears and concerns toward inhaled corticosteroid treatment for their asthmatic children. Pediatr Asthma Allergy Immunol 2005; 18: 82-87.

27. George M, Freedman TG, Norfleet AL, Feldman HI, Apter AJ. Qualitative research-enhanced understanding of patients' beliefs: results of focus groups with lowincome, urban, African American adults with asthma J Allergy Clin Immunol 2003; 111: 967-973.

28. Farber HJ, Capra AM, Finkelstein JA, et al Misunderstanding of asthma controller medications association with nonadherence. J Asthma 2003; 40: $17-25$.

29. Zedan MM, Ezz El Regal M, A Osman E, E Fouda A Steroid phobia among parents of asthmatic children Myths and truth. Iran J Allergy Asthma Immunol 2010; 9: 163-168. 